\title{
BMJ Open How socioeconomic inequalities impact pathways of care for coronary artery disease among elderly patients: study protocol for a qualitative longitudinal study
}

Sara L Schröder, ${ }^{1}$ Astrid Fink, ${ }^{1}$ Nadine Schumann, ${ }^{1}$ Irene Moor, ${ }^{1}$ Alexander Plehn, ${ }^{2}$ Matthias Richter ${ }^{1}$

To cite: Schröder SL, Fink A, Schumann N, et al. How socioeconomic inequalities impact pathways of care for coronary artery disease among elderly patients: study protocol for a qualitative longitudinal study. BMJ Open 2015;5:e008060.

doi:10.1136/bmjopen-2015008060

\section{- Prepublication history} and additional material is available. To view please visit the journal (http://dx.doi.org/ 10.1136/bmjopen-2015008060).

Received 27 February 2015 Revised 14 September 2015 Accepted 20 October 2015

CrossMark

\footnotetext{
${ }^{1}$ Institute of Medical Sociology, Martin Luther University Halle-Wittenberg, Halle (Saale), Germany ${ }^{2}$ Department of Internal Medicine III (Cardiology and Angiology), Martin Luther University Halle-Wittenberg, Halle (Saale), Germany

Correspondence to

Sara L Schröder; sara.schroeder@medizin. uni-halle.de
}

\section{ABSTRACT}

Introduction: Several studies have identified that socioeconomic inequalities in coronary artery disease (CAD) morbidity and mortality lead to a disadvantage in patients with low socioeconomic status (SES). International studies have shown that socioeconomic inequalities also exist in terms of access, utilisation and quality of cardiac care. The aim of this qualitative study is to provide information on the impact of socioeconomic inequalities on the pathway of care for $\mathrm{CAD}$, and to establish which factors lead to socioeconomic inequality of care to form and expand existing scientific theories.

Methods and analysis: A longitudinal qualitative study with 48 patients with CAD, aged $60-80$ years, is being conducted. Patients have been recruited consecutively at the University Hospital in Halle/Saale, Germany, and will be followed for a period of 6 months. Patients are interviewed two times face-toface using semistructured interviews. Data are transcribed and analysed based on grounded theory.

Ethics and dissemination: Only participants who have been informed and who have signed a declaration of consent have been included in the study. The study complies rigorously with data protection legislation. Approval of the Ethical Review Committee at the Martin-Luther University Halle-Wittenberg, Germany was obtained. The results of the study will be presented at several congresses, and will be published in high-quality peer-reviewed international journals.

Trial registration number: This study has been registered with the German Clinical Trials Register and assigned DRKS00007839.

\section{INTRODUCTION}

Socioeconomic inequality in coronary artery disease morbidity and mortality

Coronary artery disease $(\mathrm{CAD})$ is the leading cause of death in Europe. ${ }^{1}$ Its classic cardiovascular risk factors have been well

\section{Strengths and limitations of this study}

- This longitudinal qualitative study will target the impact and role of socioeconomic inequalities from the patient's perspective throughout the entire process of cardiac care provision, an area that has previously received limited research attention.

- It will provide new knowledge of key points at which the experiences of patients with different socioeconomic status (SES) diverge, thus contributing to a deeper understanding and more detailed explanation of socioeconomic inequalities in healthcare.

- It will help to develop a scientific theory and establish which factors might lead to socioeconomic inequality of care.

- In consequence of the longitudinal design, this study may have a high attrition rate.

investigated, with the most common being cigarette smoking, high cholesterol level, arterial hypertension and obesity. ${ }^{2-4}$ Countless medical, sociological and epidemiological studies have been able to demonstrate that socioeconomic inequalities in $\mathrm{CAD}$ are to the disadvantage of patients with low socioeconomic status (SES).$^{5-8}$ An Oslo Study showed that the predicted risk for CAD is more than double for men with low SES (13.3), compared to men with high SES (5.7), measured by education and income. ${ }^{6}$ The British Whitehall II Cohort Study showed that men in the lowest SES category, classified by their occupational position, have an increased risk of death compared to those in the highest category. These inequalities in cardiovascular mortality are more distinct than for all-cause mortality. ${ }^{9}$ Using crossnational data from the USA and 11 western 
European countries, Mackenbach et a $a \bar{l}$ found that cardiovascular mortality is higher among persons from a lower occupational class or with a lower level of education. Similar results regarding higher morbidity and mortality in persons with lower SES were also replicated in a German cohort. ${ }^{10}{ }^{11}$ Further studies showed that, in Great Britain, socioeconomic inequalities in CAD morbidity increased from 1960 to $1993,{ }^{8}$ and that CAD mortality increased in relative terms from 1994 to 2008, but decreased in absolute terms in the same period. ${ }^{12}$

\section{Socioeconomic inequality in access, utilisation and quality of cardiac care}

Despite relatively accurate diagnostic criteria and established therapeutic principles, ${ }^{13}$ international studies have shown inequalities in access and utilisation, also with respect to the quality of cardiac care, to the disadvantage of patients with low SES. ${ }^{14}{ }^{15}$ Furthermore, socially disadvantaged patients do not only suffer from a greater health burden and poorer outcomes, but also from less favourable conditions in access and utilisation of cardiac care, irrespective of the health system concerned. In a review, Quatromoni and Jones compiled data showing that, in the USA and in the UK, waiting times for coronary angiography (CA) and percutaneous coronary interventions (PCI)/coronary artery bypass grafts (CABG) were longer for individuals with low SES. These patients also experienced reduced rates of $\mathrm{CA}$ and $\mathrm{CABG} / \mathrm{PCI}$ compared to patients with high SES. ${ }^{15}$ Alter $e t a l^{16}$ demonstrated that more affluent or better educated patients were more likely to undergo $\mathrm{CA}$, receive cardiac rehabilitation (CR), or be followed up by a cardiologist. After adjustment, patients with high SES in New York State, measured by neighbourhood income, were $76 \%$ more likely to undergo any revascularisation procedure than were patients with low SES. ${ }^{17}$

Conversely, other studies could not find socioeconomic inequalities in access and utilisation of care. After adjustment for clinical need, the Whitehall II study showed no association in the use of cardiac procedures or prescription of secondary prevention drugs in London, using civil service employment grade as a measure of socioeconomic position. ${ }^{18}$ Mathur $e t a l^{19}$ also demonstrated that, in London, no differences in prescribing rates for recommended CAD drugs between low and high SES could be found.

Initial findings from various domains of healthcare showed that, in Germany, individuals who are socially disadvantaged and who experience a greater health burden are often among the groups that are reached least by healthcare services and also obtain the least benefit from them. ${ }^{20-22}$ Altenhöner studied socioeconomic inequalities in access, utilisation and quality of rehabilitation for patients with $\mathrm{CAD}$ in Germany; he established that CR procedures are used less frequently by patients of a lower SES. ${ }^{23}$ Conversely, a study by
Brause $e t a l^{24}$ found no socioeconomic difference for the appropriateness of a medical indication for coronary interventions in Germany.

In the majority of international studies, access and utilisation have not been clearly differentiated. Access to healthcare is predominantly a characteristic of care providers and the health system, and is influenced by geographic, financial and cultural barriers. Access is limited if offered and required health services cannot be used without these barriers. Utilisation of healthcare is predominantly a characteristic of patients, and influenced by their preferences and possibilities. ${ }^{2025}$

Factors influencing socioeconomic inequality in access, utilisation and quality of cardiac care

Only partial light has been shed on the factors that impact on socioeconomic inequalities in access and utilisation of cardiac care: Perelman et al found income-related inequalities in the use of hightechnology treatment and diagnostic techniques that could not be attributed to differences in patients' health characteristics. Those inequalities were mainly explained by inequalities in distances to hospitals with on-site cardiac facilities. ${ }^{26}$ Shanmugasegaram et $a l^{27}$ found that patients with lower subjective SES reported significantly lower referral, enrolment and participation in CR compared to patients with high subjective SES. Patients with low SES also reported significantly greater barriers to CR (eg, distance, cost and transportation problems, and the fact that it takes too long to get referred and into the programme). An increase in the overall rate of coronary revascularisation procedures in Finland resulted in a reduction in socioeconomic disparities. Nonetheless, socioeconomic inequalities continued to exist for patients with the same level of need. ${ }^{28}$

\section{Research required}

In the past, the majority of studies used a quantitative approach, often yielding merely descriptive results about the influence of SES on certain predefined factors, for example, invasive coronary procedure, CR or drug treatment. Additionally, often only one separate care sector (eg, acute care clinics or rehabilitation services) has been investigated..$^{23}$ 28-30 So far, few exploratory qualitative studies have targeted the impact and role of socioeconomic inequalities throughout the entire process of cardiac care provision. ${ }^{31} 32$ Yet, a plethora of questions, such as, how and at what point on clinical pathways socioeconomic inequalities arise, remain unanswered. So far, no comprehensive scientific theory on the factors that might lead to socioeconomic inequalities in healthcare exists. Existing models for the genesis of health inequalities assume that education, income and occupational status do not have any direct influence on health inequalities; the relationship between social inequality and inequalities in healthcare is, rather, mediated by factors. ${ }^{3-35}$ Complementary studies with a qualitative approach are fit to answer 
these questions and to help in building up a theoretic framework.

The patient's perspective has rarely been taken into account by researchers. But an in-depth understanding of the patients' experiences during care, his/her values, beliefs and disease understanding is important to expand the scientific knowledge. This will help to identify key points in the course of healthcare provision at which the experiences of patients with different socioeconomic backgrounds begin to diverge, thus contributing to a deeper understanding and more detailed explanation of socioeconomic inequalities in healthcare.

While quantitative studies can only explore the influence of SES on known factors, a qualitative study with the patient's experience at the centre of attention can also uncover previously unknown factors. A qualitative approach helps to develop a scientific theory and to provide information on the impact of socioeconomic inequalities on care, as well as establishing which factors can lead to socioeconomic inequality of care. Building on the findings, further quantitative studies can take into account other novel factors leading to socioeconomic inequality. Lastly, knowledge of the processes leading to socioeconomic differences is obligatory in order to develop and evaluate interventions aiming for equality in treatment and care for all patients.

Owing to the longitudinal study design, it is possible to obtain retrospective and prospective data of the complete clinical pathway starting from the first symptoms of $\mathrm{CAD}$. By consulting patients several times, detailed information from the patient's perspective can be obtained, and evolving and complex processes can be explored. The benefit of qualitative longitudinal studies is that a relationship of trust is established and patients are more willing to talk about deeply personal aspects during the follow-up interviews. ${ }^{36}$ Furthermore, qualitative longitudinal research can provide deep insights into the dynamic experience of illness, and change can be detected, for example, in the context of time, when a story is retold and re-interpreted by the participant at later interviews. ${ }^{37} 38$

So far, there is only limited research on socioeconomic differences in CAD treatment in Germany. The available evidence has shown socioeconomic inequalities in access and utilisation, but no clear influence of SES has been identified in the conducted studies. Owing to the fact that the German healthcare system provides comprehensive coverage for most medical and hospital services, it is not based on user fees at the point of healthcare services. Patients have to pay very low out-of-pocket payments, limited to $1-2 \%$ of their annual gross income. ${ }^{39}$ This circumstance should provide equitable access based on medical needs rather than SES. This contradiction is addressed in this study through finding factors that cause socioeconomic differences of $\mathrm{CAD}$ care in Germany.

\section{METHODS AND ANALYSIS}

\section{Aims}

This study will investigate socioeconomic inequality in access, utilisation and quality across different stages of care in $\mathrm{CAD}$, from hospitalisation in an acute care clinic, to rehabilitation and subsequent outpatient treatment by a general practitioner (GP) and a cardiac specialist.

The aim of this explorative study is to answer the following research questions:

1. What impact do socioeconomic inequalities have on the access to, and the utilisation and quality of, healthcare services during the particular stages of healthcare for patients with CAD?

2. Can specific factors and mechanisms that lead to inequality of healthcare be identified?

3. How do socioeconomic inequalities interact and accumulate over the course of treatment and care?

\section{Study design}

A qualitative design is used to answer these research questions. This allows for an open approach, enabling the scope, depth and complexity of the subjective perspectives of patients with CAD to be analysed in their own social and cultural context. The study is being conducted as a single-centre qualitative longitudinal study in Halle/Saale, Saxony-Anhalt, Germany, a high-risk area for poverty and CAD mortality. ${ }^{41}$

\section{Sample selection and recruitment}

Patients with CAD have been recruited consecutively over a period of 6 months at the Department of Internal Medicine III (Cardiology and Angiology) at the University Hospital Halle/Saale, Germany, and will be followed up for a period of 6 months. The first interview was conducted with 48 patients aged 60-80 years who suffer from CAD. In order to cover the greatest possible variety and diversity of experiences in relation to access, utilisation and quality of care, patients were sampled purposively using a maximum variation sampling strategy until theoretical saturation was reached. Patients with the most frequent clinical manifestations-stable angina pectoris, acute coronary syndrome and cardiac arrhythmia-have been selected and grouped. In accordance with the maximum variation sampling strategy, we aimed to recruit one-third of patients with each clinical manifestation and around half of the patients from a high SES group. Additionally, we aimed to recruit around $50 \%$ women, and took multimorbidity and different levels of severity of CAD into account. Nineteen $(40 \%)$ women and 29 men were interviewed at T1. Thirty-four $(71 \%)$ patients were multimorbid, 27 (56\%) patients had a long history of CAD and thereby long-time experiences with care, and 18 (37.5\%) patients had a higher severity of CAD with three vessel disease, stenosis of the left mainstem, stents, or a bypass. The distribution of the patients to diagnosis and SES can be found in table 1 . 
Table 1 Sample of patients with CAD interviewed at baseline (T1)

\begin{tabular}{lllc}
\hline $\begin{array}{l}\text { Diagnosis: CAD in } \\
\text { combination with }\end{array}$ & Total & High SES & Low SES \\
\hline Stable angina pectoris & 14 & 6 & 8 \\
Acute coronary syndrome & 18 & 7 & 11 \\
Cardiac arrhythmia & 16 & 8 & 8 \\
Total & 48 & 21 & 27 \\
\hline
\end{tabular}

CAD, coronary artery disease; SES, socioeconomic status.

The patients' inclusion criteria for participating in the study were:

- Age 60-80 years,

- With CAD as the principal or secondary diagnosis,

- One additional other principal or secondary diagnosis: stable angina pectoris, acute coronary syndrome or cardiac arrhythmia.

Patients were excluded from the study if they fulfilled one of the following criteria:

- Insufficient language skills to conduct an interview in the German language,

- Other heart diseases excluding CAD,

- Moribund patients.

The abort criterion is:

- Withdrawal of consent by the patient before or during the interview.

Enrolment started in November 2014. Patients meeting inclusion criteria were identified by a study nurse at the Department of Internal Medicine III at the University Hospital Halle/Saale and informed about the study by means of an information sheet. If the patient was interested in participating, an appointment was arranged prior to their estimated discharge date, and a researcher of the project team explained the study to the patient. Patients were given comprehensive information and enrolled in the study after providing written informed consent. If the patient attended the first interview, he/she will be contacted by a project team member 6 months later by post and telephone to schedule a second interview. Enrolment was completed in April 2015.

\section{Data collection}

A researcher conducted 48 baseline interviews (T1) at the acute hospital. In order to protect patient privacy and to provide a comfortable atmosphere for the conversation, the interviews were conducted in a separate, undisturbed room in the hospital, where patients could not be interrupted or overheard by attending physicians, nursing staff or other patients. The second interview (T2) will be conducted 6 months after discharge from the acute hospital. The patients are free to decide whether the second interview will be conducted in their own homes or on the premises of the Institute of Medical Sociology.

The same researcher questions patients face-to-face on the two data collection dates using guided interviews.
The interviews do not exceed a maximum time of $45 \mathrm{~min}$, and digital recordings made are with the interviewee's consent. Guidelines based on the methods used by Helfferich have been developed for the semistructured qualitative interviews; these contain key questions that evoke narrations, supplemented by areas of conversation around specific topics and specific supplementary questions, as well as questions aimed at maintaining the conversational flow. ${ }^{42}$ The interview guides for $\mathrm{T} 1$ and T2 (see online supplementary files) were pilot-tested on two patients with CAD before any data was collected.

The following key questions were asked during the baseline interview:

- Please begin by telling me about the medical history of your heart disease, starting from the first symptoms until this hospital stay.

- What positive and negative factors have you experienced concerning the care you have received?

- How would you describe the quality of your treatment?

- How do you currently manage your heart disease?

In order to collect data on SES and other sociodemographic variables, questions were asked about the patients' age, gender, nationality, marital status, level of schooling, occupational training qualifications and profession. These data have been collected verbally in a standardised way at the end of the first guided interview, T1.

In the follow-up interview, T2, the following key questions will be asked:

- Please begin by telling me how the treatment of your heart disease has progressed after our last conversation.

- What positive and negative factors have you experienced concerning the treatment and care you have received?

- Last time we talked about your expectations of your medical care-to what extend have they been fulfilled?

- What kind of influence does your heart disease have on your everyday life?

- What will happen next?

\section{Socioeconomic status}

Patients are allocated to a group with high or low SES based on their level of schooling and academic qualifications. The classification is based on German epidemiological standards. ${ }^{43}$ Information on the patient's highest level of schooling and his/her highest occupational training qualification is merged in a range that rates education on a scale of 1-8. Values from 6 to 8 points are considered high SES, this includes all patients with A-Level and all with a degree from university or technical school. Patients with $<6$ points are classified as having a low SES; this includes mainly patients with 10 or less years at school and a company-based apprenticeship. In addition to educational level, we also measure the current or last occupation. This allows us to 
investigate whether there are any inconsistencies between occupation and education regarding the patient's SES. ${ }^{44}$ Data on income have not been collected to determine SES. For older people, pensioner income is a problematic indicator for SES for several reasons. First, retirement is often associated with a decline in income and therefore financial assets are considered to be a better measure than income for SES of older people. Second, income presents a sensitive personal issue, and questions on this topic thus frequently remain unanswered. ${ }^{456}$

\section{Data analysis}

After conducting the interviews, the recordings are transcribed by a transcription agency and pseudonyms are used to protect personal data. Transcribed interviews are analysed in accordance with Glaser and Strauss' rules of grounded theory. ${ }^{47}$ MAXQDA software is used to assist with the data management and analyses. Using grounded theory, the codes are generated openly and inductively from the text in the first instance. Categories are then identified from the developed codes, and relationships will be made between them (axial coding). As a last step, a key category is identified using selective coding. The other categories are related both to one another and to the key category. Memos play a very important role at each stage of coding in grounded theory, because they represent the hypotheses and thoughts of the researcher that are formed during coding, comparison and evaluation of the interviews. The memos help the researcher to bring his/her thoughts to their logically consistent conclusion. Through a method of constant comparison, a key element of grounded theory, the statements made during the interviews at two different times can be compared with one another, and be related to one another. Finally, similarities and differences in the patients' situations, beliefs and experiences of care between the two points of interviews are identified. ${ }^{48}$ Information from low SES groups are compared to that from high SES groups. The qualitative research group at the Institute of Medical Sociology is involved in discussion and evaluation of the data to ensure a high quality of the results. Lastly, the consolidation criteria for reporting qualitative research (COREQ) are taken into account during the research process to ensure high quality in qualitative research. ${ }^{49}$

\section{ETHICS AND DISSEMINATION}

The Committee has expressed no ethical issues about the study. The study complies rigorously with data protection legislation. Before interviews began to be conducted, patients were informed about the study in an information sheet and gave their written informed consent. Participation is voluntary and may be withdrawn at any point during the study. A withdrawal of one's consent is possible at any time; in such cases, all data will be deleted. Each patient is assigned a unique pseudonym, and all data are compiled under this pseudonym; this will prevent any individuals or places from being identified and will ensure that all personal data are protected. The name of the patient is not to be mentioned during the interview in order to prevent the interviews and transcripts from being associated with any individual. The study data, personal data and list assigning pseudonyms to individuals are stored securely at separate locations. Only authorised members of the research team have access to the declaration of consent and the pseudonym assignment list. Once all data has been collected, the pseudonym assignment list will be deleted. Because of the close cooperation with the Department of Internal Medicine III at the University Hospital Halle/Saale, patients might feel inhibited about criticising their hospital stay. Accordingly, the attending physician will not be involved in the recruitment for the study. In addition, the initial interview was conducted in a separate room at the clinic at the end of the hospital stay, so that the patient could express himself/herself freely, without any concerns about potential consequences for their treatment. The second interview will be conducted either in the patient's home or on the facilities of the Institute of Medical Sociology.

The results of the study will be presented at several congresses and research conferences, and will be published in one PhD thesis (SLS), and in high-quality peerreviewed international journals.

\section{CONCLUSION}

This study will provide further evidence, from the patient's perspective, on the impact of socioeconomic inequalities in healthcare for $\mathrm{CAD}$ and on central factors that might lead to socioeconomic inequality. It will explicitly address different sectors of healthcare, and will provide meaningful insights on socioeconomic risk groups. With the knowledge gained of the mediating aspects between SES and inequalities in healthcare, present theoretical models can be expanded and made more specific with respect to the production of health inequalities. The results of this study can be used to empirically investigate theories of how unequally distributed socioeconomic factors influence access, utilisation and quality of care, and to develop interventions reducing these inequalities.

Contributors SLS wrote the initial draft of this manuscript, will conduct the further interviews and analyse the data. MR is responsible for the conception of the project, led the grant application and critically reviewed the manuscript. MR and AF wrote the original study protocol in collaboration with AP, NS and IM. All the authors have read and approved the final version of the manuscript.

Funding This work is supported by the Wilhelm Roux Programme for the funding of young scientists and research of the Medical Faculty of Martin Luther University, Halle-Wittenberg, grant number FKZ: 28/40.

Competing interests None declared.

Ethics approval Ethical Review Committee of the Medical Faculty of Martin Luther University, Halle-Wittenberg. 
Provenance and peer review Not commissioned; externally peer reviewed.

Open Access This is an Open Access article distributed in accordance with the Creative Commons Attribution Non Commercial (CC BY-NC 4.0) license, which permits others to distribute, remix, adapt, build upon this work noncommercially, and license their derivative works on different terms, provided the original work is properly cited and the use is non-commercial. See: http:// creativecommons.org/licenses/by-nc/4.0/

\section{REFERENCES}

1. Nichols $M$, Townsend $\mathrm{N}$, Scarborough $\mathrm{P}$, et al. Cardiovascular disease in Europe: epidemiological update. Eur Heart $J$ 2013:34:3028-34.

2. Heinemann LA, Garbe E, Classen E, et al. Trends im kardiovaskulären Risikofaktorenprofil in Ostdeutschland. Dre unabhängige Bevölkerungsuntersuchungen im Rahmen des Projekts MONICA Ostdeutschland. MONItoring of Trends and Determinants of CArdiovascular Disease. Dtsch Med Wochenschr 1998;123: 889-95.

3. Tyroler HA. Coronary heart disease epidemiology in the 21st century. Epidemiol Rev 2000;22:7-13.

4. Kannel WB. New perspectives on cardiovascular risk factors. Am Heart J 1987:114:213-19.

5. Mackenbach JP, Cavelaars AE, Kunst AE, et al. Socioeconomic inequalities in cardiovascular disease mortality; an international study. Eur Heart J 2000;21:1141-51.

6. Holme I, Helgeland A, Hjermann I, et al. Coronary risk factors and socioeconomic status. The Oslo study. Lancet 1976;2:1396-8.

7. Smith GD, Hart C, Blane D, et al. Lifetime socioeconomic position and mortality: prospective observational study. BMJ 1997;314: 547-52.

8. González MA, Rodríguez Artalejo F, Calero JR. Relationship between socioeconomic status and ischaemic heart disease in cohort and case-control studies: 1960-1993. Int J Epidemiol 1998;27:350-8

9. Stringhini S, Berkman L, Dugravot A, et al. Socioeconomic status, structural and functional measures of social support, and mortality: the British Whitehall II Cohort Study, 1985-2009. Am J Epidemiol 2012;175:1275-83.

10. Helmert U, Herman B, Joeckel $\mathrm{KH}$, et al. Social class and risk factors for coronary heart disease in the Federal Republic of Germany. Results of the baseline survey of the German Cardiovascular Prevention Study (GCP). J Epidemiol Community Health 1989;43:37-42.

11. Schumann B, Kluttig A, Tiller D, et al. Association of childhood and adult socioeconomic indicators with cardiovascular risk factors and its modification by age: the CARLA Study 2002-2006. BMC Public Health 2011;11:289.

12. McCartney $D$, Scarborough $P$, Webster $P$, et al. Trends in social inequalities for premature coronary heart disease mortality in Great Britain, 1994-2008: a time trend ecological study. BMJ open 2012;2: e000737.

13. Montalescot G, Sechtem U, Achenbach S, et al. 2013 ESC guidelines on the management of stable coronary artery disease: the Task Force on the management of stable coronary artery disease of the European Society of Cardiology. Eur Heart $J$ 2013;34:2949-3003.

14. Jones L, McDaid C, Hartley S, et al. Inequalities in cardiac services: a scoping review: NHS Centre for Reviews and Dissemination. http://www.york.ac.uk/inst/crd/pdf/prpcardiac.pdf (accessed 18 Feb 2015).

15. Quatromoni J, Jones R. Inequalities in socio-economic status and invasive procedures for coronary heart disease: a comparison between the USA and the UK. Int J Clin Pract 2008;62:1910-19.

16. Alter DA, Iron K, Austin PC, et al. Socioeconomic status, service patterns, and perceptions of care among survivors of acute myocardial infarction in Canada. JAMA 2004;291:1100-7.

17. Philbin EF, McCullough PA, DiSalvo TG, et al. Socioeconomic status is an important determinant of the use of invasive procedures after acute myocardial infarction in New York State. Circulation 2000;102 (19 Suppl 3):III107-15

18. Britton A, Shipley M, Marmot M, et al. Does access to cardiac investigation and treatment contribute to social and ethnic differences in coronary heart disease? Whitehall II prospective cohort study. BMJ 2004;329:318

19. Mathur R, Badrick E, Boomla K, et al. Prescribing in general practice for people with coronary heart disease; equity by age, sex, ethnic group and deprivation. Ethn Health 2011;16:107-23.
20. von dem Knesebeck O, Bauer U, Geyer S, et al. Soziale Ungleichheit in der gesundheitlichen Versorgung-Ein Plädoyer für systematische Forschung. Gesundheitswesen 2009;71:59-62.

21. Klein J, Hofreuter-Gätgens K, Von dem Knesebeck O.

Socioeconomic status and the utilization of health services in Germany: a systematic review. In: Janßen C, Swart E, von Lengerke $\mathrm{T}$, eds. Health care utilization in Germany theory, methodology, and results. New York: Springer, 2014:117-43.

22. Janßen $\mathrm{C}$, Frie $\mathrm{K}$, Dinger $\mathrm{H}$, et al. Der Einfluss von sozialer Ungleichheit auf die medizinische und gesundheitsbezogene Versorgung in Deutschland. In: Richter M, Hurrelmann K, eds. Gesundheitliche Ungleichheit Grundlagen, Probleme, Perspektiven. Wiesbaden: VS, Verl. für Sozialwissenschaften, 2009:149-65.

23. Altenhöner T. Soziale Ungleichheit in der kardiologischen Rehabilitation: Eine empirische Unter-suchung sozialer Ungleichheit in der Rehabilitation von Herzinfarktpatienten. Lage: Jacobs, 2006.

24. Brause M, Grande G, Mannebach H, et al. Der Einfluss sozialer und struktureller Faktoren auf die Angemessenheit invasive kardiologischer Prozeduren. Medizinische Klinik 2006;101:226-34.

25. Pfaff $H$, Schrappe M. Einführung in die Versorgungsforschung. In: Pfaff H, Neugebauer EA, Glaeske G, et al., eds. Lehrbuch Versorgungsforschung: Systematik-Methodik-Anwendung. Stuttgart: Schattauer, 2011:2-39.

26. Perelman J, Shmueli A, McDonald KM, et al. Inequality in treatment use among elderly patients with acute myocardial infarction: USA, Belgium and Quebec. BMC Health Serv Res 2009;9:130.

27. Shanmugasegaram S, Oh $\mathrm{P}$, Reid RD, et al. Cardiac rehabilitation barriers by rurality and socioeconomic status: a cross-sectional study. Int J Equity Health 2013;12:72.

28. Hetemaa T, Keskimäki I, Manderbacka K, et al. How did the recent increase in the supply of coronary operations in Finland affect socioeconomic and gender equity in their use? $J$ Epidemiol Community Health 2003;57:178-85.

29. Alter DA, Naylor CD, Austin $P$, et al. Effects of socioeconomic status on access to invasive cardiac procedures and on mortality after acute myocardial infarction. N Engl J Med 1999;341:1359-67.

30. Pilote L, Tu JV, Humphries K, et al. Socioeconomic status, access to health care, and outcomes after acute myocardial infarction in Canada's universal health care system. Med Care 2007;45: 638-46.

31. Tod AM, Read C, Lacey A, et al. Barriers to uptake of services for coronary heart disease: qualitative study. BMJ 2001;323:1-6.

32. Manderbacka K. Exploring gender and socioeconomic differences in treatment of coronary heart disease. Eur J Public Health 2005;15:634-9.

33. Whitehead M, Dahlgren G. Levelling up (part 2): a discussion paper on concepts and principles for tackling social inequities in health. Copenhagen, Denmark: World Health Organization, Regional Office for Europe, 2006.

34. Marmot M, Friel S, Bell R, et al. Closing the gap in a generation: health equity through action on the social determinants of health Lancet 2008;372:1661-9.

35. Mielck A. Soziale Ungleichheit und Gesundheit: Einführung in die aktuelle Diskussion: Einführung in die aktuelle Diskussion. 1st edn. Bern: Huber, 2005.

36. Murray SA, Boyd K, Kendall M, et al. Dying of lung cancer or cardiac failure: prospective qualitative interview study of patients and their carers in the community. BMJ 2002;325:929.

37. Carduff E, Murray SA, Kendall M. Methodological developments in qualitative longitudinal research: the advantages and challenges of regular telephone contact with participants in a qualitative longitudinal interview study. BMC Res Notes 2015;8:142.

38. Lewis J. Analysing qualitative longitudinal research in evaluations. Soc Policy Soc 2007;6:545-56.

39. Sozialgesetzbuch Fünftes Buch: SGB V

40. Stang A, Stang M. An inter-state comparison of cardiovascular risk factors in Germany: towards an explanation of high ischemic heart disease mortality in Saxony-Anhalt. Dtsch Arztebl Int 2014;111: 530-6.

41. Deutsche Herzstiftung, eds. Deutscher Herzbericht 2013: 25 Bericht/ Sektorenübergreifende Versorgungsanalyse zur Kardiologie und Herzchirurgie in Deutschland. Frankfurt am Main: Deutsche Herzstiftung, 2014.

42. Helfferich C. Die Qualität qualitativer Daten: Manual für die Durchführung qualitativer interviews. 3rd edn. Wiesbaden: VS Verlag für Sozialwissenschaften, 2009.

43. Jöckel K, Babitsch B, Bellach B, et al. Messung und Quantifizierung soziographischer Merkmale in epidemiologischen Studien. In: Ahrens W, Bellach B-M, Jöckel K-H., eds. Messung soziodemographischer Merkmale in der Epidemiologie. München: MMV Medizin Verlag, 1998:7-38. 
44. Horan PM, Gray BH. Status inconsistency, mobility and coronary heart disease. J Health Soc Behav 1974;15:300-10.

45. Grundy E, Holt G. The socioeconomic status of older adults: how should we measure it in studies of health inequalities? J Epidemiol Community Health 2001;55:895-904.

46. Robert S, House JS. SES differentials in health by age and alternative indicators of SES. J Aging Health 1996;8: 359-88.
47. Glaser BG, Strauss AL. The discovery of grounded theory: strategies for qualitative research. New Brunswick: Aldine Publication, 1999.

48. Breuer F, Dieris B. Reflexive grounded theory: Eine Einführung für die Forschungspraxis. Wiesbaden: VS, Verlag für Sozialwissenschaften, 2009.

49. Tong A, Sainsbury P, Craig J. Consolidated criteria for reporting qualitative research (COREQ): a 32-item checklist for interviews and focus groups. Int J Qual Health Care 2007;19:349-57. 